\title{
OS CAMINHOS DA CODICOLOGIA
}

Antonio Ackel ${ }^{\star}$

iD http://orcid.org/0000-0002-8283-4417

\section{Maria de Fátima Nunes Madeira**}

(iD) http://orcid.org/0000-0001-6141-0714

Como citar este artigo: ACKEL, A.; MADEIRA, M. de F. N. Os caminhos da codicologia. Todas as Letras - Revista de Lingua e Literatura, São Paulo, v. 23, n. 1, p. 1-15, jan./abr. 2021. DOI 10.5935/1980-6914/eLETDO2114359

Submissão: março de 2021. Aceite: março de 2021.

Resumo: Este trabalho pretende traçar uma história da codicologia desde a sua fundamentação como ciência autônoma até o entendimento que se tem a partir da automação digital implementada em sua área de atuação. Para tanto, consideram-se os pressupostos teóricos e metodológicos da codicologia tradicional, aliados às humanidades digitais para apresentar um programa de identificação e registro das marcas d'água em documento manuscrito, o qual também facilita seu processo de localização em banco de dados específico, para assim obter as informações sobre sua origem e datação.

Palavras-chave: Codicologia. Humanidades digitais. Documento digital. Marca d’água. Banco de dados. 


\section{INTRODUÇÃO}

$\mathbf{A}$

Codicologia, a Paleografia e a Diplomática, para citar apenas três das principais ciências essenciais na realização de pesquisas históricas, filológicas e linguísticas, por exemplo, são algumas vezes designadas como auxiliares, adjetivo equivocado quando vistas como adicionais, acessórias ou até dispensáveis.

Spina (1994, p. 23, 65 e 82) relaciona a Paleografia, a Diplomática e a Codicologia aos seus objetos de estudo, distingue esses conhecimentos como indispensáveis para a investigação filológica e denomina auxiliares à Filologia disciplinas como a Literatura, a História, a Geografia e a Gramática.

Azevedo Filho (1987, p. 19) designa como auxiliares, e ao mesmo tempo como indispensáveis, a Paleografia, a Codicologia e a Diplomática.

Castro (1997, p. 604) afirma que algumas funções e preocupações da Filologia desencadearam novas disciplinas, que são entre si solidárias por visarem ao texto e à sua escrita, dentre elas, a Paleografia e a Codicologia.

Barbosa (2008, p. 207) conclui que essas ciências se auxiliam mutuamente:

As pesquisas historiográficas, filológicas e linguístico-históricas alternam-se entre si no papel de ciência auxiliar a depender dos objetivos, do quadro teórico, das questões e objetos de cada investigação. Elas se entreveem ora por janelas, ora por frestas abertas em seu inexorável ponto de contato: o texto escrito.

Este artigo faz referência a hipóteses sobre o estatuto de ciência autônoma que a Codicologia possui, não só por estabelecer teoria e método para desvendar seu objeto de estudo, como para mostrar que, como outros saberes, tem proposto novos olhares para o suporte, os digitais.

Poderia parecer precoce pensar em uma subárea, denominada Codicologia Digital, na medida em que há certo preconceito sobre a máquina fazer o trabalho do homem ao segurar e observar um documento de perto. No entanto, podem ser citados projetos desenvolvidos para que a descrição e a análise documental material se atualizem com auxílio da informática, como os de Rehbein, Sahle e Shaßan (2009) e Shen et al. (2014).

Dessa maneira, propomos iniciar a leitura deste trabalho com uma perspectiva do termo codicologia e das suas funções. Por isso, na primeira seção, apresentaremos o conceito e as técnicas da Codicologia como ciência que estuda os elementos materiais que compõem um documento escrito.

Em seguida, apresenta-se uma breve visão historiográfica de sua trajetória como disciplina, desde a sua origem, no século XVIII, até a atualidade, e da utilização dos métodos de pesquisa disponiveis, ao longo desse caminho, para o aprimoramento das análises da materialidade do manuscrito e do códice.

$\mathrm{Na}$ terceira seção, a Codicologia é apresentada em seu papel de disciplina que analisa o contexto sociocultural do documento, descrevendo as suas formas de produção, circulação, preservação e transmissão, até chegar ao leitor contemporâneo.

$\mathrm{Na}$ quarta parte, buscaremos relacionar a Codicologia às Humanidades Digitais, tendo em vista a transposição do texto escrito para o suporte digital.

$\mathrm{Na}$ última seção, apresentaremos um exemplo de recurso tecnológico para a identificação de marcas d'água, um vestígio presente em documentos históricos, 
de fundamental importância para a realização da análise de autenticidade do manuscrito, unindo, dessa forma, a Codicologia ao meio digital.

\section{As técnicas da Codicologia}

A Codicologia pode ser definida como a disciplina que se preocupa com a configuração de um documento. Busca conhecer a história do texto por meio da observação e descrição dos elementos utilizados para sua confecção. Nesse sentido, a Codicologia torna-se também responsável por assegurar o restauro e a conservação de patrimônios documentais. Além disso, ao se conceber o documento como um artefato histórico, a Codicologia permite entender algumas características do material utilizado no manuscrito e com isso contextualizar sua produção.

Uma vez observados os suportes maleáveis, como o papiro, os pergaminhos e os papéis, a Codicologia torna-se a disciplina primeira que ensina a identificar os elementos que constituem a materialidade de um documento por meio das condições e aparência de um suporte textual.

Por materialidade entende-se toda resposta que se tenha de um documento a partir do contato direto, por exemplo, sentir sua textura e seu peso, olhar contra a luz, verificar dobras, manchas, rasgos, carimbos, anotações de terceiros etc. Ao observar o fólio, o codicologista consegue examinar, por exemplo, a disposição do texto principal (conhecido como mancha), o número total de linhas manuscritas, a utilização ou não de margens e parágrafos na composição textual, destaques de fragmentos como datas tópica e cronológica, vocativo, assinatura e escritos posteriores, por exemplo. O virar de uma página, o aproximar dos olhos ao documento são ações que permitem ao pesquisador participar de uma etapa da qual o leitor final de seu trabalho normalmente não compartilha.

Ainda que se possam conjecturar hipóteses acerca das condições de um documento, utilizando-se imagens digitais, é impossível assegurá-las sem esse contato. O pesquisador deve colocar as mãos no documento e conhecê-lo, é assim que os saberes codicológicos se constituem plenamente e adicionam informações para o estudo da obra.

No entanto, essa atividade tem se tornado cada vez menos executada por conta da digitalização e acesso que arquivos, bibliotecas, universidades têm disponibilizado em seus portais na internet. Assim, torna-se necessário aproveitar o que a automação digital pode oferecer à Codicologia, unindo ciências de variados campos que permitam ampliar o conhecimento sobre um documento.

A codicologia, por sua natureza, compartilha interesses e objetos com diversas ciências. Tem estreito parentesco com a história, mas não menos que com a filologia ou com a arte, para citar os casos mais evidentes. Tais relações múltiplas constituem uma fonte de riqueza intelectual, já que as orientações metodológicas e as técnicas aplicadas em outros campos do saber são suscetiveis a extrapolarem para o nosso âmbito (GARCÍA, 2002, p. 25, tradução nossa) ${ }^{1}$.

\footnotetext{
No original: "La codicología, por su propia naturaleza, comparte intereses y objetos con diversas ciencias. Tiene estrecho parentesco con la historia, pero no menos con la filología o el arte, por citar los casos más evidentes. Tales relaciones múltiples constituyen una fuente de riqueza intelectual, ya que las orientaciones metodológicas y las técnicas aplicadas en otros campos del saber son susceptibles de extrapolarse a nuestro propio ámbito".
} 
Segundo Gilissen (1977, p. 244), um documento manuscrito é um artefato histórico e, como tal, deve ser analisado. É certo que contam a sua história, mas quando documentos textuais são estudados apenas por seus escritos, outra grande riqueza de conhecimento, sua história, deixa de ser revelada. Com isso, limita-se o acesso ao documento, deixando-se de considerá-lo sob outras perspectivas acerca do seu dimensionamento, não só linguístico, como também político e cultural.

Um documento manuscrito pode, num primeiro momento, revelar-se uma folha de papel com inscrições, carimbos, dobras, tudo com motivos e fins variados, mas o aprofundamento do olhar sobre o objeto pode levar a questionamentos subjacentes àquela elaboração. Sua configuração documental, quer dizer, o registro material feito no documento, além de suas características físicas, pode revelar ao observador o propósito e o uso de um manuscrito, tanto a partir do momento de sua produção quanto de seu encaminhamento. O estudo dessa configuração adiciona fatos à história do documento e, assim, permite aprofundar o conhecimento sobre sua edição.

\section{CODICOLOGIA: UMA RECUPERAÇÃo HISTÓRICA}

A codicologia, disciplina que se ocupa de livros e documentos manuscritos, está presente nos estudos filológicos há pouco mais de três séculos. Nasceu em 1708, com a Palaeographia graeca, de Montfaucon, mas seus contornos começaram a ser mais bem delimitados em 1817, em Zur Handschriftenkunde, de Ebert. A prática codicológica foi definida, em 1818, por Ersch e Gruber, em Allgemeine Encyklopädie der Wissenschaften und Künste, como a soma da formação e da técnica acadêmica sobre as várias propriedades de livros escritos à mão. Foi nessa obra também que os autores propuseram codicologia como uma ciência separada, com existência própria e independente. No entanto, estudiosos de ciências filológicas perceberam que ainda faltavam trabalhos com tratamento detalhado de todas as partes do manuscrito (GUMBERT, 1989).

Durante os 200 anos seguintes, estudos notáveis deram importantes contribuições à codicologia, incluindo os excelentes manuais Prolégomenes a la codicologie, de Gilissen (1977); La descrizione del manoscritto: storia, problemi, modelli, de Petrucci (1984); Introducción a la codicologia, de García (2002); Il libro manoscrito da Oriente e Ocidente per una codicologia comparata, de Agati (2009).

Ainda durante muito tempo, a Codicologia permaneceu entremeada às práticas paleográficas. Paleógrafos, até os anos 1950, buscavam descobrir autenticidades e datações nas informações encontradas para além das escrituras nos livros manuscritos. O primeiro estudioso a defender a Codicologia como "ciência dos livros" foi Charles Samaran, que, em suas aulas durante os anos de 1934 e 1935, na École Pratique des Hautes Etudes, advogou a independência da disciplina quando definiu o termo "codicografia", entendido como termo paralelo à "bibliografia". No entanto, o termo não foi aceito nas comunidades acadêmicas e acabou dando lugar ao que hoje conhecemos como "codicologia", termo cunhado por Alphonse Dain em Les manuscripts (1949). O autor atribuiu esse nome a partir dos estudos que Mallon vinha desenvolvendo, especialmente em sua obra Paleographie romaine, de 1952. Após discussões e concessões, Samaran (1961) publica L'histoire e ses méthode, e, a partir daí, a Codicologia desenvolve-se vigorosamente e estabelece-se como escola. 
A arqueologia do livro manuscrito (Codicologia) estuda os materiais utilizados para confecção de livros e sua implementação. Disciplina que exige paciência, atenção aos detalhes e espírito de observação, a Codicologia permite resolver certos problemas até então insolúveis (SAMARAN, 1961, p. 1.085, tradução nossa) ${ }^{2}$.

Pioneiro por pensar sobre a estrutura material dos manuscritos medievais, Charles Samaran formulou pela primeira vez os conceitos da ciência codicológica. Gumbert (1989, p. 7, tradução nossa) aprimorou os estudos de Samaran e propôs as terminologias unité codicologique (unidade codicológica) e césure (cesura), concebendo o primeiro como

[...] parte de um livro resultante de uma atividade que pode ser considerada unitária em relação ao tempo, lugar e circunstâncias e o último como um "limite de caderno que é ao mesmo tempo um limite de texto ou de algum outro aspecto codicológico"3.

Trata-se do estabelecimento de uma sintaxe do códice, ou seja, uma sistematização que ajuda a identificar as unidades codicológicas de um manuscrito que correspondem a diferentes etapas da produção - e a relação entre elas. $\mathrm{O}$ problema torna-se mais complexo nos casos em que o manuscrito já passou por várias etapas de produção, sofreu perdas ou acréscimos, ou contém unidades codicológicas discretas - com textos diferentes - de origens e naturezas diversas.

Mais recentemente, em um notável esforço de sistematização tipológica, Patrick Andrist, Paul Canart e Marilena Maniaci (2013) propuseram uma estrutura estratigráfica e a análise sintática dos códices, incluindo exemplos da maioria das possiveis anomalias materiais e textuais que podem ser encontradas nos manuscritos, permitindo descrevê-los e fornecer melhores respostas às questões textuais e históricas colocadas pelos próprios códices.

A palavra codicologia é uma definição que nasce da combinação do latim e do grego, com o termo latino codex - icis, caudex - icis (códice), que designava tronco de árvore (no qual as letras do alfabeto estavam gravadas), e depois, por metonimia, as tábuas feitas de madeira, adequadamente tratadas para criar um suporte de escrita, códice (AGATI, 2009, p. 29), adicionado ao sufixo grego -logia

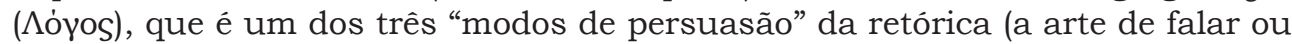
escrever de forma eficaz), juntamente com o ethos e o pathos. Logos é um argumento que busca senso de lógica ou razão de um público (BENTHAM, 2019).

Os códices, em sua constituição material, eram ligados por meio de anéis para formar um bloco. O termo passou a designar o ajuntamento de papiro ou de pergaminho costurados. Códice indica, portanto, a forma preservada do livro (embora com características diferentes) até os dias atuais e que, a partir do século I d.C., aproximadamente, foi substituindo os volumes, ou rolos, sendo passado sob essa forma do Antigo Egito para o mundo greco-romano. Códice refere-se ao livro em sua materialidade concreta, ou seja, aquela em que a ideia abstrata do autor encontra, por meio de sua editoração, a realização física para alcançar o produto final: o livro.

2 No original: "L'archéologie du livre manuscrit (codicologie), étude des matériaux servant à la confection du livre et leur mise en ouvre. Discipline exigeant patience, minutie et esprit d'observation, la codicologie permet de résoudre certains problèmes jusquelà insolubles".

3 No original: "[...] partie d'un livre résultant $d$ ' une activité qui peut être considérée comme unitaire sous le rapport du temps, du lieu et des circonstances' e 'une limite de cahier qui est en même temps une limite de texte ou de quelque autre aspect codicologique". 
O termo "manuscrito", por sua vez, deve sua designação ao contraste com a tipografia, que, alterando técnicas de produção e publicação, estabelece uma divisão na história do livro. Pode referir-se a qualquer tipo de escrita que não seja impressa (autógrafos, documentos, escrituras, inventários etc.), de qualquer idade e em qualquer suporte, no entanto, o uso no sentido primário de um livro, como suporte de texto (literário, filosófico, jurídico, religioso etc.) destinado à circulação e comércio, copiado por um amanuense (e, portanto, dentro de limites cronológicos claros) e realizado com materiais diferenciados que determinam épocas distintas em sua evolução.

Numa tentativa de encontrar respostas para as várias incógnitas, a Codicologia procura, por intermédio de todas as pistas úteis, antes de tudo, "interpretar as condições da produção original de um livro de uma maneira tradicional" (LEMAIRE, 1989, p. 4), ou seja, como um produto artesanal, o livro ou documento manuscrito, é único e, como tal, deve ser estudado e avaliado, investigando-se a complexa rede de fatores da qual é resultado não aleatório; e é um "mistério arqueológico" (LEMAIRE, 1989, p. 4), cujos fatos materiais antes apurados pela arqueologia devem ser submetidos à história para propor sua explicação.

A partir dessa premissa, outros estudos, centrados no mesmo objeto de estudo (o livro ou códice e o documento manuscrito em suas diversas formas, mais primitivas ou modernas), propuseram, ao longo dos anos 1970, que a disciplina pudesse ser diferenciada em duas áreas para além da "arqueologia do livro": a codicologia lato sensu e a codicologia scricto sensu.

A codicologia scricto sensu observa a forma, os suportes, os instrumentos e todos os procedimentos de fabricação para que o livro ou o documento manuscrito chegue à sua realização. Nesse sentido, essa codicologia pode ser considerada a arqueologia do livro, a ciência de seus componentes materiais ou conjunto de características físicas.

A codicologia lato sensu aborda os manuscritos como objeto cultural e textual, portanto, requer um grau de estudo que não se concentre apenas na descrição material do objeto. Alguns estudiosos - principalmente historiadores - entendem que a codicologia lato sensu deve incluir produção, uso, transmissão e significado de um livro ou documento em seu contexto cultural.

O estudo desses dois aspectos está intimamente relacionado:

[...] é a disciplina histórico-filológica que tem como objeto o estudo do manuscrito, mais precisamente do códice ou livro de manuscritos, em todos os seus aspectos, tanto formais quanto textuais (CASAMASSIMA, 1964, p. 181, tradução nossa) ${ }^{4}$.

A codicologia, portanto, vai além do estudo do livro como um produto artesanal, de interesse meramente arqueológico. Assim, o significado do termo "codicologia" varia de um autor para outro. Por exemplo, Maniaci (2002, p. 10, tradução nossa) afirma que "os materiais constituintes, as técnicas de fabricação, os métodos de execução e a apresentação do livro manuscrito são, portanto, parte do território 'natural' da codicologia"5; Agati (2009, p. 22, tradução nossa) propõe codicologia como uma ciência integral que

4 No original: "[...] è la disciplina storico-filologica che ha per oggetto lo studio del manoscritto, più precisamente del codice o libro manoscritto, in ogni suo aspetto, sia formale che testuale".

5 No original: "I materiali costitutivi, le tecniche di fabbricazione, le modalità esecutive e la presentazione del libro manoscritto fanno quindi parte del territorio 'naturale' della codicologia". 
[...] não ignora a interatividade com as disciplinas filológica e paleográfica, que abordam diferentes aspectos da mesma realidade do códice; a disciplina evoca aspectos como transcrição, autenticidade, decoração, história do arquivamento e, acima de tudo, conservação e catalogação ${ }^{6}$.

Hoje, essa ciência faz uso de métodos de pesquisa que são cada vez mais refinados, como técnicas laboratoriais em constante evolução, graças às quais é possivel determinar as espécies animais utilizadas na fabricação do pergaminho, a madeira utilizada ou os componentes do papel, das tintas e pigmentos; é possivel também medir com precisão a espessura de um suporte ou fazer com que as escrituras apagadas ressurjam nos fólios.

\section{Codicologia E PRODUÇÃo SOCIAL}

Para que se compreendam as configurações e características de livros e documentos manuscritos como artefatos históricos, faz-se necessário observar sua consistência, qualidade, textura; medir sua dimensão, formato, superficie escrita, espaçamento entre linhas; encontrar rasgos, deteriorações; identificar técnicas utilizadas na confecção do papel, como as filigranas ou marcas d'água (imagem formada por diferenças na espessura de uma folha de papel, aplicando-se uma estampa na folha ainda úmida. Pode ser vista apenas quando o papel é colocado contra a luz, não interferindo no que está escrito ou impresso), as vergaturas (linhas paralelas, unidas e finas, produzidas pelos fios metálicos do tear da forma para a fabricação do papel) e os pontusais (linhas perpendiculares produzidas pelos fios metálicos do tear da forma para a fabricação do papel), para ajudar na datação do artefato.

Figura 1 - Filigrana, vergaturas e pontusais

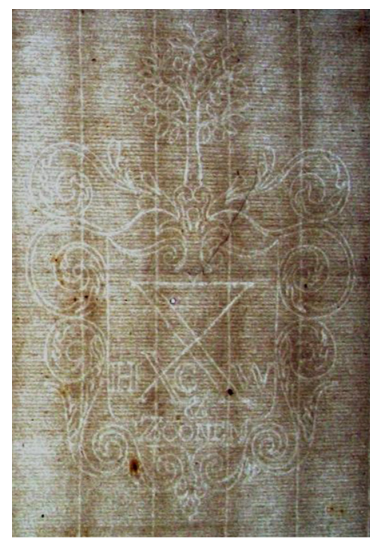

Fonte: Reprodução fotográfica realizada pelos autores.

O estudo da materialidade centra-se na ideia de produção social como parte integrante de uma época (TILLEY, 1990, p. 47). Entender a materialidade de um

6 No original: "[...] non ignora la interattività con le discipline filologiche e paleografiche, le quali costituiscono solo un approcio diferente alla stessa realtà-codex; e neppureelude aspetti come la transcrizione, la leliggibilità, la decorazione, la storia delle biblioteche e, sopratutto, la conservazione e catalogazion". 
documento permite conjecturar suas origens, modos de transmissão, circulação, lugares de pouso, razões de produção e, a partir disso, exceder o limite de uma descrição física documental para oferecer possibilidades de conjecturações oferecidas pela Filologia, desde a utilização de um tipo específico de instrumento para a composição do texto até conseguir percorrer o caminho que o documento fez para chegar às mãos do leitor.

A utilização da narrativa acima reforça a necessidade de se firmarem estudos descritivos e analíticos no campo da Codicologia. Há os que buscam informações não apenas sobre os fatos, mas sobre as razões que os levaram a se consumar. $\mathrm{O}$ documento, inserido nessa estrutura contextualizadora, pode revelar tais informações, corroborando a ideia de concebê-lo como fonte escrita para a pesquisa histórica (LARA, 2008, p. 22). A resposta pode ser conjecturada a partir da forma de produção, utilização e destinação do documento. É preciso partir do modo como o documento foi constituído e manuseado para entendê-lo, a partir de suas múltiplas funções (PETRUCCI, 2008, p. 54). Essa tarefa é possivel quando são pesquisados também os eventos ocorridos diacronicamente à produção do manuscrito; trata-se de avaliar as circunstâncias em que foi elaborado para delas averiguar os dados pertinentes às respostas que se buscam.

Uma vez estabelecidos os critérios de avaliação que serão adotados em um manuscrito, pode-se focar o que se pretende descobrir e, de acordo com a perspectiva, mesmo que limitado o campo de atuação na investigação codicológica, serão descobertas diferentes particularidades, cada uma revelando uma técnica própria.

Ao longo de sua circulação, um documento manuscrito revela sinais de alteração em sua constituição. Tais modificações podem ser observadas sob vários aspectos, por exemplo: 1. material, com alterações no estado físico do suporte, carimbos, rasgos, dobras, corrosões por insetos, umidade; 2. substancial, com alterações na composição imagética/estética do documento, anotações nas margens, autorais ou não, datas, vocativos, assinaturas destacadas; 3. histórico, com alterações no curso de uma transmissão ou do lugar de pouso, leituras e anotações alheias, manipulação e posse indevida.

O objeto que resulta de cada uma dessas intervenções não tem mais a mesma característica de antes. Nesse sentido, pode-se dizer que o artefato textual é um objeto evolutivo que permite estudos diacrônicos e sincrônicos.

O estudo de um documento manuscrito deve compreendê-lo em sua característica concreta, material, corpórea. Trata-se de conceber o documento como testemunho real da história que conta, entendê-lo como objeto de registro pertencente à época em que foi elaborado. É sob esse aspecto que pode o filólogo analisar seu objeto de estudo e investigar sua validade, identidade, valor, autenticidade.

Ao serem analisadas as informações impressas pela mão do homem com seu instrumento em um documento, quer sejam suas escrituras, quer sejam seus desenhos, quer sejam suas rasuras, o pesquisador é levado a considerar informações gráficas existentes no suporte. O manuscrito pode ser considerado essencialmente como portador de uma mensagem escrita que é transmitida ao longo do tempo, e assim deve ser preservado como testemunha de uma época. Como tal, passa a ser uma representação de um fenômeno social e cultural, produto de uma atividade intelectual.

É um instrumento condicionado pela função que a ele se atribui e que determina sua circulação à circunstância sob a qual nasceu, porém tal circulação 
pode ser alterada, a depender do contexto social, cultural e histórico em que se insere.

Anotações de terceiros, furos, rasgos e outras interferências no manuscrito podem representar camadas de identidade documental (ACKEL, 2019). A cada estágio de modificação substancial do documento, sua identidade se reconfigura e ele passa a possuir diferentes utilidades. A serventia de uma informação é definida a partir do interesse que se tem sobre ela.

Ainda sob um ponto de vista da Codicologia, cujo interesse também reside nos aspectos gráfico-visuais do documento, ou seja, na forma de distribuir o material textual no suporte, pode-se pensar inversamente sobre essas marcas e observar os espaços em branco. A ausência da escrita também pode revelar qualidades do documento e de seu autor, por exemplo, quando recuos de parágrafos, vocativos centralizados e separados da mancha, assinaturas feitas no fim do texto com margem à direita ou outros itens gráficos são posicionados de forma organizada e pensada na folha de papel, é de se conjecturar a educação formal que teve seu autor.

Para García (2002, p. 22), o manuscrito revela sua mensagem quando comparado com outros exemplares da mesma procedência. Podem-se utilizar documentos que foram elaborados em papéis iguais ou com o mesmo instrumento e verificar que uma determinada anotação de terceiro difere entre um documento e outro, por exemplo. As condições do papel também podem revelar informações sobre sua transmissão, circulação, manuseio, por exemplo, sob a forma como foi dobrado ou sob os furos de grampeador feitos nas margens.

Enfim, concordando com Almada (2014), as marcas deixadas nos suportes são informações preciosas sobre as formas de uso, apropriação, circulação e também pelas práticas de sua preservação. E cabe à Codicologia realizar a investigação de todos esses aspectos no manuscrito e no códice.

\section{Codicologia e Humanidades Digitais}

As disciplinas filológicas, que se debruçam sobre os documentos escritos com o objetivo de fixar o texto e analisar seus aspectos materiais para, afinal, não só averiguar sua autenticidade e fidedignidade, mas, principalmente, torná-lo compreensível ao leitor contemporâneo, têm deparado já há algumas décadas com o texto - manuscrito ou impresso - no ambiente digital.

As vantagens, principalmente do acesso, a bibliotecas e arquivos universais garantem a democratização das consultas, tanto do ponto de vista dos pesquisadores, que não mais precisam fazer longos deslocamentos para buscar seus objetos de estudo, quanto do patrimônio escrito disponivel no mundo, que pode chegar a todos os consulentes de bancos de dados, independentemente de sua localização física.

Essa transformação do texto e de seu suporte para a forma eletrônica também tem sido discutida pela Filologia, principalmente a partir da aplicação dos conhecimentos das Humanidades Digitais ${ }^{7}$ no labor filológico.

7 "A multiplicação de projetos e iniciativas identificados sob o rótulo de 'Humanidades Digitais' ao redor do mundo é acompanhada por uma multiplicação de acepções distintas do próprio rótulo: ele é usado para designar ora um conjunto de práticas, ora um novo campo acadêmico. O chamado Manifesto das Humanidades Digitais, composto por ocasião do ThatCamp 2010, trata as Humanidades Digitais como uma 'transdisciplina' que incorpora os métodos, os dispositivos e as perspectivas heurísticas das ciências humanas e sociais, ao mesmo tempo em que mobiliza as ferramentas e perspectivas singulares abertas pela tecnologia digital" (PAIXÃO DE SOUSA, 2011, p. 112). 
Uma preocupação principal entre filólogos, arquivistas e bibliógrafos tem concentrado a sua atenção principalmente nos cuidados necessários com a identificação, a catalogação, a preservação e principalmente com o acesso eficaz a todos esses dados digitais.

A impossibilidade de se analisarem os aspectos materiais de um texto digital tem sido suplantada pela iniciativa de arquivos e bibliotecas ${ }^{8}$, que, utilizando tecnologias computacionais, apresentam, nos catálogos, os itens codicológicos sobre o testemunho, como o tipo de suporte, o número de fólios, colunas e linhas, o tipo de escrita, a cor da tinta, as miniaturas, iluminuras e demais detalhes ornamentais, o tipo de encadernação etc.

As Humanidades Digitais, presentes atualmente na Filologia com estudos e importantes soluções para questões da análise paleográfica e diplomática, bem como com edições digitais de textos tanto manuscritos quanto impressos, abrem caminho para inovações também nos estudos codicológicos.

Aspecto fundamental para a análise codicológica na averiguação da autenticidade e datação, principalmente em documentos diplomáticos (atos escritos de origem governamental e/ou notarial), é a origem do papel ${ }^{9}$. E, para essa investigação, as marcas d'água configuram item primordial, já que a partir de uma filigrana é possivel identificar o fabricante do papel, o país onde foi fabricado e a data de fabricação, possibilitando, com esses dados, a verificação da correspondência entre a datação do documento, os fatos descritos no texto, a origem e a circulação do papel que contém a referida marca d'água.

\section{UMA PROPOSTA PARA A IDENTIFICAÇÃO DE MARCA D’ÁGUA EM MANUSCRITO DIGITAL}

Normalmente, os trabalhos de Filologia que analisam documentos escritos em papel descrevem marcas d'água nos aspectos codicológicos desses textos.

O reconhecimento de marcas d'água é um problema prático para arquivistas e historiadores, na medida em que as informações de data cronológica e tópica associadas a cada marca d'água são uma pista importante para analisar e avaliar documentos históricos.

Ainda são escassas as pesquisas brasileiras sobre o reconhecimento automático de marcas d'água. Isso se deve à dificuldade de se criar um conjunto de dados a partir de arquivos públicos, em que seria possivel, por exemplo, acessar uma grande variedade de marcas d'água diferentes de um lugar e em sequência cronológica ou ainda ter muitos exemplos da mesma marca d'água em papéis em diferentes estados de conservação e escritos por diferentes mãos. Uma quantidade de dados suficientes para análise e comparação de marcas d'água permitiria criar variadas hipóteses para a pesquisa documental.

8 Como exemplo, veja-se a The Morgan Library \& Museum, cujo patrimônio documental pode ser acessado em: https://www. themorgan.org

9 Para mais informações sobre a história e fabricação do papel e das filigranas, sugerimos a leitura da dissertação de mestrado Estudo do papel e das filigranas e sua correspondência em manuscritos dos séculos XVIII e XIX na capitania e província de Mato Grosso (OLIVEIRA, 2014). 
Há alguns métodos criados para esse fim que vão desde desenhar à mão uma marca d'água com uma folha de papel sob ela até a utilização das caras técnicas radiográficas que avaliam a espessura do papel (BOUTAINE; IRIGOIN; LEMONNIER, 1974). Há também o Dylux, que usa um papel suscetivel à luz visivel e ultravioleta para definir marcas d'água (TOMIMASU et al., 1991). Hoje em dia não é mais permitido em muitas bibliotecas e museus por causar danos à saúde do pesquisador e do suporte.

Consideramos aqui a criação de um conjunto de dados, ainda bastante elementar, com a intenção de identificar e classificar marcas d'água. Testes iniciais foram feitos com digitalizações por meio de retroiluminação ${ }^{10}$, conforme o esquema abaixo, em documentos pertencentes à coleção Alberto Lamego, do Instituto de Estudos Brasileiros da Universidade de São Paulo (IEB/USP) ${ }^{11}$.

Figura 2 - Imagem transversal do papel com dados no recto, verso e a marca d'água

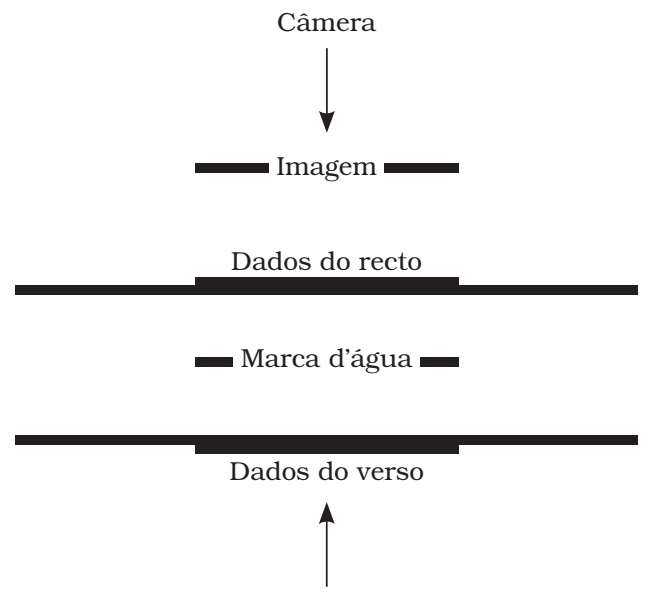

Fonte de luz

Fonte: Elaborada pelos autores.

Uma vez digitalizadas, faz-se a remoção da imagem do fólio, constituída pelo suporte e por todos os símbolos gráficos nele contidos. Sem adentrarmos em termos técnicos, procede-se com uma edição da imagem, exagerando seus contrastes, de forma que a marca d'água fique visivel. Na Figura 3, pode-se observar as fases de edição até chegar a uma imagem binária que representa a forma aproximada da marca d'água ${ }^{12}$.

10 A técnica de retroiluminação requer uma câmera digital de alta resolução e uma fonte de luz. A câmera captura imagens refletidas no recto do fólio pelo contraste que a fonte de luz, que está no verso do suporte, oferece (HIARY, 2008).

11 Em 2017, a Faculdade de Letras da USP ofereceu uma disciplina de Filologia que foi ministrada no IEB/USP. Os documentos utilizados fazem parte da coleção Lamego. Na época, já com intenção de trabalhar com pesquisas codicológicas, digitalizamos grande quantidade de documentos e temos trabalhado com eles desde então.

12 Trata-se do manuscrito assinado em nome do padre Antonio Vieira, em Roma, em 23 de maio de 1650 , dando instruções e conselhos ao príncipe Dom Theodozio, primogênito do Rei Dom João IV. Está disponível somente para consulta pessoal sob o código de referência 135-007 e armazenado na caixa 18, códice 135, sala 01, da coleção Alberto Lamego, do IEB/USP. 
DOSSIE

Figura 3 - Imagem de etapas de edição por contraste
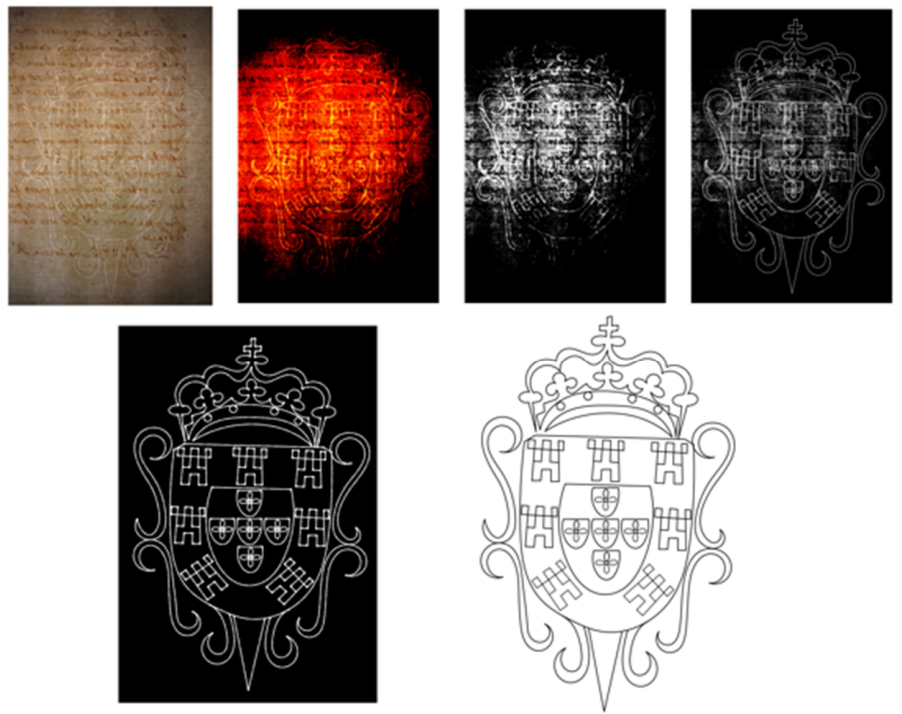

Fonte: Elaborada pelos autores.

Note-se que nem sempre é necessária uma representação precisa ou completa da marca d'água. Por exemplo, um modelo aproximado de um fragmento de marca d'água pode ser delineado pelo usuário a partir de um modelo apenas ou pela comparação de vários exemplares.

Uma vez que o sistema aprende a reconhecer as marcas d'água, pode-se avaliar algoritmos de aprendizado profundo para reconhecimento da diferença entre elas. Apenas como um teste inicial, demonstramos um resultado do processo de diferenciação de imagens ${ }^{13}$.

Figura 4 - Diferenciação automática de marcas d'água
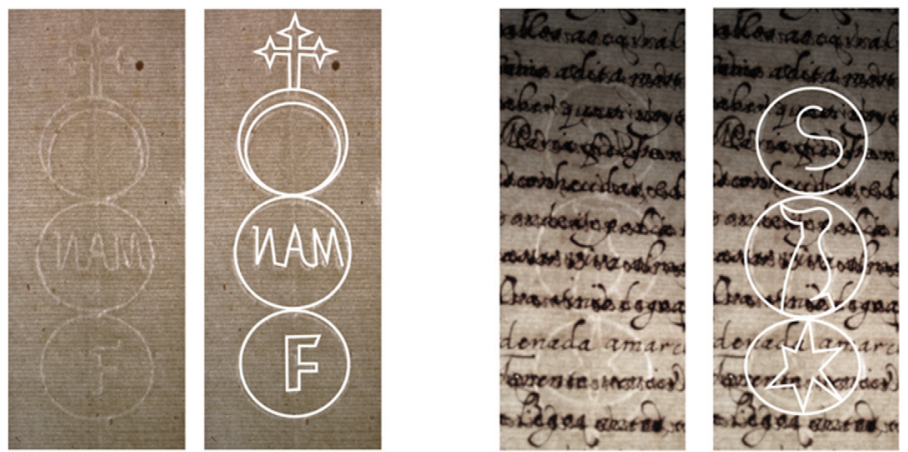

Fonte: Elaborada pelos autores.

\footnotetext{
13 As imagens podem ser encontradas no códice 135, sob o código de referência 214, armazenado na caixa 44 da coleção Alberto Lamego, e pode ser consultado no IEB/USP. Trata-se de uma coleção documental do século XIX sobre a exportação de bens brasileiros para a Europa.
} 
Mesmo estando no mesmo códice, pode-se identificar uma procedência diferente dos papéis, por conta de sua marca d'água. A partir dessa informação e com acesso a grandes bancos de dados de filigranas, um conjunto de marcas d'água de documentos brasileiros permitiria que o usuário visualizasse informações codicológicas como procedências, datação cronológica e outros elementos que poderão ser utilizados para a reconstrução de fatos que circunstanciaram a produção documental.

Há diversos bancos de dados disponiveis na internet, como: Dutch University Institute for Art History Watermark Database ${ }^{14}$; Warwick Centre for the Study of Renaissance - LIMA Database ${ }^{15}$; Archive of Watermarks and Papers in Greek Manuscripts, do Bates College ${ }^{16}$; Bernstein Consortium, A Memória do Papel ${ }^{17}$.

O objetivo ulterior dessa proposta é a criação de mais uma fonte de pesquisa para que estudiosos procurem informações que correspondam às marcas d'água encontradas por eles em outros manuscritos, por meio da exploração das vantagens do meio eletrônico.

\section{CONSIDERAÇÕES FINAIS}

Cabe à Codicologia descrever e relacionar, no contexto de produção, circulação e transmissão de documentos e todos os elementos físicos que compõem o manuscrito registrado em papel (no caso deste estudo), avulso ou encadernado, como: o tipo de papel, as vergaturas e os pontusais, as filigranas, o número, a dimensão e a organização dos fólios na página, a dimensão da mancha, o número e o tamanho das colunas, o tipo de paginação, a presença de assinaturas, as particularidades, as marcas especiais, as iluminuras, as miniaturas, os carimbos, o ex-libris, a datação, o local de origem, o tipo de encadernação, o material, a natureza e a cor da cobertura, a decoração e os demais detalhes na capa, nos nervos e no lombo de um códice. E também os rasgos, as dobras, os furos, os grampos, as anotações de terceiros e até os espaços em branco.

Nos seus três séculos de existência, acompanhando os tempos em que se desenvolveu como ciência autônoma, a Codicologia fez usos dos métodos de pesquisa mais apropriados para realizar essas funções.

Da mesma forma, atualmente, a metodologia codicológica se vale de técnicas laboratoriais, principalmente químicas e fisicas, para realizar análises refinadas sobre a fabricação do papel e das tintas, o que contribui para uma datação ainda mais precisa dos documentos.

Como o próprio texto sofreu transformações, nos últimos tempos, tendo assumido características eletrônicas, as Humanidades digitais têm oferecido ferramentas para a realização das tarefas filológicas a partir de iniciativas dos próprios filólogos.

Nesse contexto, apontamos propostas iniciais para a extração de marcas d'água do papel, a partir de uma digitalização por retroilulminação. Com isso, vislumbramos a implementação de um banco de dados de marcas d'água em documentos brasileiros.

\footnotetext{
14 Disponível em: http://www.wm-portal.net/niki/index.php

15 Disponível em: https://warwick.ac.uk/fac/arts/ren/archive-research-old/lima/paper/describing/databases

16 Disponível em: https://abacus.bates.edu/wmarchive/overview.html

17 Disponível em: http://www.bernstein.oeaw.ac.at/
} 
Com base neste estudo inicial, esperamos inspirar novas propostas de pesquisas, envolvendo a Codicologia e as ciências computacionais, para aprimorar as possibilidades de análise dos elementos materiais de um texto digitalizado.

\section{CoDicology PATHWAYS}

Abstract: This work intends to trace a history of codicology from its establishment as an autonomous science until the digital automation implemented in its area. For this purpose, theoretical and methodological assumptions of traditional codicology are considered, and together with digital humanities, we propose the first step to create a database system that identifies and classifies watermarks in handwritten documents. Our aim is to facilitate the process of locating watermarks in a specific database in order to obtain information on Brazilian documents.

Keywords: Codicology. Digital Humanities. Digital documents. Watermark. Database.

\section{REFERÊNCIAS}

ACKEL, A. Cartas pessoais de pacientes do Sanatório Pinel (1929-1944): um estudo filológico. 2019. Dissertação (Mestrado em Filologia e Língua Portuguesa) Universidade de São Paulo, São Paulo, 2019. Disponivel em: https://www.teses.usp.br/teses/disponiveis/8/8142/tde-20022020-165247/pt-br.php. Acesso em: 10 jan. 2021.

AGATI, M. L. Il libro manoscritto da Oriente a Occidente. Per una codicologia comparata. Roma: L'Erma di Bretschneider, 2009.

ALMADA, M. Cultura escrita e materialidade: possibilidades interdisciplinares de pesquisa. PÓS: Revista do Programa de Pós-graduação em Artes da EBA/ UFMG, v. 4, n. 8, p. 134-147, 2014. Disponivel em: https://periodicos.ufmg.br/ index.php/revistapos/article/view/15485. Acesso em: 10 fev. 2021.

ANDRIST, P.; CANART, P.; MANIACI, M. La syntaxe du codex. Essai de codicologie structural. Bélgica: Brépols. 2013.

AZEVEDO FILHO, L. A. Iniciação em crítica textual. Rio de Janeiro: Presença Edições; São Paulo: Edusp, 1987.

BARBOSA, A. G. Fontes escritas e história da língua portuguesa no Brasil: as cartas de comércio no século XVIII. In: LIMA, I. S.; CARMO, L. História social da lingua nacional. Rio de Janeiro: Edições Casa de Rui Barbosa, 2008.

BENTHAM, J. Logos. In: DUIGNAN, B. (ed.) Encyclopaedia Britannica. 2019. Disponivel em: https://www.britannica.com/topic/logos. Acesso em: 15 jan. 2020.

BOUTAINE, J.-L.; IRIGOIN, J.; LEMONNIER, A. La radiographie dans l'étude des manuscrits. CNRS, p. 159-175, 1974.

CASAMASSIMA, E. Per una storia delle dottrine paleografiche dall'Umanesimo a Jean Mabillon. Studi Medievali, p. 177-193, 1964.

CASTRO, I. Enciclopédia Verbo das literaturas de lingua portuguesa. Lisboa: Verbo, 1997. 
DAIN, A. Les manuscripts. Paris: Les Belle Lettres, 1949.

GARCÍA, E. R. Introducción a la codicologia. Madrid: Biblioteca del Libro, 2002. GILISSEN, L. Prolégomenes a la codicologie. Recherches sur la construction des cahiers et la mise en page des manuscrits médiévaux. Gand: Story-Scientia, 1977.

GUMBERT, J. P. L'unité codicologique ou: à quoi bon les cahiers? Gazette du Livre Médiéval, n. 14, p. 4-8, 1989.

HIARY, H. Paper-based watermark extraction with image processing. 2008. Tese (Doutorado em Computação) - University of Leeds, Leeds, 2008.

LARA, S. H. Os documentos textuais e as fontes do conhecimento histórico. Revista Anos 90, Porto Alegre, v. 15, n. 28, p. 17-39, 2008.

LEMAIRE, J. Introduction à la codicologie. Louvain-la-Neuve: Université Catholique de Leuven, 1989.

MALLON, J. Paléographie romaine. Madrid: Scripturae monumenta et studia, 1952.

MANIACI, M. Archeologia del manuscritto. Metodi, problemi, bibliografia recente. Roma: Viella, 2002.

OLIVEIRA, G. M. Estudo do papel e das filigranas dos séculos XVIII e XIX na capitania e província de Mato Grosso. 2014. Dissertação (Mestrado em Letras) Universidade Federal de Mato Grosso, Cuiabá, 2014. Disponivel em: https://ri. ufmt.br/handle/1/333. Acesso em: 20 jan. 2021.

PAIXÃO DE SOUSA, M.C. Humanidades digitais? Um breve panorama. 2011. Disponivel em: https://nehilp.prp.usp.br Acesso em: 10 fev. 2021.

PETRUCCI, A. La descrizione del manoscritto. Milano: Carocci, 1984.

PETRUCCI, A. Scrivere lettere. Una storia plurimillenaria. Bari: Editori Laterza, 2008.

REHBEIN, M.; SAHLE, P.; SHAßAN, T. Kodikologie und Paläographie im digitalen Zeitalter - Codicology and Palaeography in the Digital Age. Norderstedt: Herstellung un Verlag, 2009. Disponivel em: https://core.ac.uk/download/ pdf/12010507.pdf. Acesso em: 20 jan. 2021.

SAMARAN, C. Notes manuscrites de son cours de l'année 1934-35 à l'École Pratique des Hautes Etudes. Paris, 1934-1935.

SAMARAN, C. L'Histoire et ses méthodes. Paris: Gallimard, 1961.

SHEN, Y. et al. Learning semantic representations using convolutional neural networks for web search. The International Conference on World Wide Web, Seoul, v. 4, n. 32, p. 373-374, 2014.

SPINA, S. Introdução à edótica: crítica textual. São Paulo: Ars Poética: Edusp, 1994.

TILLEY, C. Reading material culture. Oxford: Blackwell, 1990.

TOMIMASU, H. et al. Comparison of four paper imaging techniques: beta-radiography, electrography, light transmission, and soft X-radiography. Tappi, v. 74, n. 7, p. 165-176, 1991. 